\title{
River monitoring from satellite radar altimetry in the Zambezi River basin
}

\author{
C. I. Michailovsky ${ }^{1}$, S. McEnnis ${ }^{1}$, P. A. M. Berry ${ }^{2}$, R. Smith ${ }^{2}$, and P. Bauer-Gottwein ${ }^{1}$ \\ ${ }^{1}$ Department of Environmental Engineering, Technical University of Denmark, Miljøvej, Building 113, \\ 2800 Kgs. Lyngby, Denmark \\ ${ }^{2}$ Earth and Planetary Remote Sensing Laboratory, De Montfort University, The Gateway, Leicester, LE19BH, UK
}

Correspondence to: C. I. Michailovsky (cibm@env.dtu.dk)

Received: 29 February 2012 - Published in Hydrol. Earth Syst. Sci. Discuss.: 12 March 2012

Revised: 5 June 2012 - Accepted: 22 June 2012 - Published: 20 July 2012

\begin{abstract}
Satellite radar altimetry can be used to monitor surface water levels from space. While current and past altimetry missions were designed to study oceans, retracking the waveforms returned over land allows data to be retrieved for smaller water bodies or narrow rivers. The objective of this study is the assessment of the potential for river monitoring from radar altimetry in terms of water level and discharge in the Zambezi River basin. Retracked Envisat altimetry data were extracted over the Zambezi River basin using a detailed river mask based on Landsat imagery. This allowed for stage measurements to be obtained for rivers down to $80 \mathrm{~m}$ wide with an RMSE relative to in situ levels of 0.32 to $0.72 \mathrm{~m}$ at different locations. The altimetric levels were then converted to discharge using three different methods adapted to different data-availability scenarios: first with an in situ rating curve available, secondly with one simultaneous field measurement of cross-section and discharge, and finally with only historical discharge data available. For the two locations at which all three methods could be applied, the accuracies of the different methods were found to be comparable, with RMSE values ranging from 4.1 to $6.5 \%$ of the mean annual in situ gauged amplitude for the first method and from 6.9 to $13.8 \%$ for the second and third methods. The precision obtained with the different methods was analyzed by running Monte Carlo simulations and also showed comparable values for the three approaches with standard deviations found between 5.7 and $7.2 \%$ of the mean annual in situ gauged amplitude for the first method and from 8.7 to $13.0 \%$ for the second and third methods.
\end{abstract}

\section{Introduction}

Hydrological models are widely used by water resources managers to obtain river flow predictions, and significant effort has gone into the improvement of models' predictive capabilities. One of the key steps of modeling is the calibration/validation phase in which modeled and measured quantities are compared. For hydrological models, this is typically carried out using in situ discharge measurements. However, in spite of the usefulness of such datasets, river discharge monitoring has globally declined over the past few decades leaving many of the world's river basins un- or sparsely monitored (Fekete and Vörösmarty, 2007), and timely data availability is often a problem even in well monitored areas. Remote sensing data has stepped in to complement or replace in situ model input data for many hydrologically relevant datasets such as precipitation (e.g. Stisen and Sandholt, 2010), temperature, reference evapotranspiration (Schmugge et al., 2002) and topography (with the Shuttle Radar Topography Mission; Farr et al., 2007), among others (see Tang et al., 2009 for a review). Remote sensing data can also be used to obtain data useful in the calibration/validation step of modeling such as actual evapotranspiration (e.g. Stisen et al., 2008), soil moisture (Wagner et al., 1999; Aubert et al., 2003) or total water storage (e.g. Tapley et al., 2004; Milzow et al., 2011).

While no current remote-sensing technique is capable of directly measuring discharge, radar altimeters measure water surface elevation over rivers, which can then be converted to discharge. Past and current satellite altimetry missions including Geosat, TOPEX/Poseidon, ERS-1, ERS-2 
and Envisat were primarily designed to study oceans and ice caps but they have nonetheless been collecting large amounts of data over inland waters (Calmant et al., 2008). The first applications of continental altimetry focused on lakes (e.g. Morris and Gill, 1994; Birkett, 1995). Koblinsky (1993) showed the potential for using radar-altimetry in river level monitoring in the Amazon basin where Geosatderived river levels were found to have a $70 \mathrm{~cm}$ root mean square error (RMSE) relative to in situ measurements. Birkett (1998) studied the performance of TOPEX/Poseidon over floodplains and large rivers in many basins and showed that for rivers of widths above $1.5 \mathrm{~km}$, the TOPEX/Poseidon altimeter was able to track river levels, finding a mean RMSE relative to gauged level of $60 \mathrm{~cm}$ over the Amazon River. Most studies only consider large lakes and rivers as the retracking algorithms used rely on the echoes returned from the water surface to be ocean-like in shape (Berry et al., 2005). Berry et al. (2005) showed that by retracking individual echo shapes, data could be retrieved from a much larger proportion of the Earth's river systems, and from smaller water bodies, than was previously thought. In a study of the Mekong River, considering rivers with widths of down to $400 \mathrm{~m}$, Birkinshaw et al. (2010) found RMSE values of 0.44 to $0.65 \mathrm{~cm}$ for retracked Envisat data.

Because river discharge rather than water level is usually the variable of interest to hydrologists, the next step after acquiring river stage measurements is conversion to discharge. In traditional in situ river discharge monitoring, a rating curve relating water level to discharge is established by simultaneous measurement of flow and discharge at different flow levels and a curve is fitted through the measured points (Chow et al., 1988). Water levels are typically recorded on a daily basis and discharge obtained through the rating curve. The same approach can be used for the conversion of altimetry data to discharge when such a rating curve is available at the location of the crossing of the satellite track over the river system (crossings will be referred to as virtual stations or VS in the remainder of the article). This can be done either by applying the in situ rating curve to the altimetry-derived water levels or by developing a specific rating curve directly relating altimetry water levels to in situ discharge (e.g. Kouraev et al., 2004; Zakharova et al., 2006). For situations where no in situ data are available at the VS, Bjerklie et al. (2003) proposed a method based on remote sensing data only that relies on the measurement of hydraulic data from space and multiple regression analysis of discharge measurements to derive the discharge equations. Using hydrological models calibrated with in situ data at other locations in the basin, Leon et al. (2006) and Getirana et al. (2009) developed methods to derive rating curves at VS locations based on altimetric levels and modeled discharges.

Radar altimeter data has also been used to improve modeled discharge estimates in calibration and assimilation frameworks. Getirana (2010) showed that altimetric river levels could be used in the automatic calibration of a hydrological model of the Branco River basin, providing knowledge of the stage-discharge relationship at the measurement location. Studies preparing for the upcoming Surface Water Ocean Topography Mission (SWOT) have shown that combining virtual swath altimetric measurements with hydrodynamic models in a data assimilation framework improved modeled depth and discharge on river stretches where the bathymetry is assumed to be known (Andreadis et al., 2007; Biancamaria et al., 2011).

This study focuses on altimetry data for monitoring of water levels and discharge in the Zambezi River basin (ZRB). The ZRB covers $1390000 \mathrm{~km}^{2}$ and is the largest river basin in Southern Africa. It is one of Africa's main water resources providing water for human consumption, irrigation of crops as well as hydropower and is shared between eight countries. This study aims to present a realistic assessment of the potential for altimetry in the basin.

Results were obtained over the basin for rivers with a minimum width of $80 \mathrm{~m}$ using river masks derived from Landsat imagery and stage-to-discharge capabilities were systematically assessed for three different approaches corresponding to three different data availability scenarios: existence of an in situ rating curve, availability of one simultaneous measurement of stage and discharge from a field visit, and availability of historical discharge data.

\section{Materials and methods}

\subsection{Altimetry data and extraction}

The altimetric stage data used for this study is the RAT (Radar AlTimetry) product derived at the Earth and Planetary Remote Sensing Lab (EAPRS) from the $18 \mathrm{~Hz}$ Envisat waveforms (Berry et al., 2005). Each waveform is the average of 100 consecutive individual echoes along the orbit. The averaging is done on board the satellite to produce the $18 \mathrm{~Hz}$ waveforms with $369 \mathrm{~m}$ along-track spacing. To obtain the RAT product, the waveforms are retracked using one of 12 possible retrackers, the most appropriate retracker being chosen for each waveform based on the shape of the returned signal. The different retrackers allow for altimetric heights to be derived from complex waveforms. The footprint of each waveform is of approximately $2-10 \mathrm{~km}$ over oceans but is significantly smaller over land surfaces. If a water body is located within the footprint, it will usually dominate as the return signal is much stronger over water than over land.

The data obtained from EAPRS covers the entire area of the Zambezi basin. The first step was to select data corresponding to virtual stations. The return period for Envisat is of 35 days, meaning that a data point is available every 35 days at each VS, provided there is no loss of lock on the underlying terrain by the altimeter. The coordinate of each RAT data point is that of the first of the 100 averaged waveforms. RAT points therefore contain data from waveforms 
located up to $369 \mathrm{~m}$ from their location in the along-track direction. For each virtual station, RAT data points were therefore selected if the river was located within $365 \mathrm{~m}$ from the point in the along-track direction. For larger rivers where more than one data point were available per satellite overpass, the selection distance from the river was reduced in order to limit the contamination from other surfaces. Detailed river masks at VS locations were extracted from Landsat imagery by computing the Normalized Difference Vegetation Index (NDVI). Typical NDVI values for open water range between -1 and -0.1 . A threshold for open water delineation was determined for each VS after visual inspection of the imagery. Threshold values were found to be between -0.1 and -0.3 , depending on the surroundings and the size of the river. This method can be compared to the semi-automatic method used by Roux et al. (2010).

An additional selection was conducted based on the backscatter coefficient (sigma 0 expressed in $\mathrm{dB}$ ), which is a function of the power of the signal returned at the altimeter and can be used to detect surface water (e.g. Birkett, 2000). This is especially useful for locations where the river width varies greatly between wet and dry seasons as seasonal variations in river width were not directly taken into account in the extraction procedure. A threshold value of $20 \mathrm{~dB}$ was chosen.

Outliers in altimetry time series can occur for a number of reasons such as, for example, contamination by land or the altimeter locking onto an off-nadir target (Frappart et al., 2006) and must be removed from the dataset. For each VS time series, outliers were removed by applying the following procedure:

- The mean value, $m$ and the standard deviation, $\sigma$, of the altimetry elevation $h$ were computed.

- For each altimetry value, $h_{i}$, the point was rejected if $\left|h_{i}-m\right|>3 \cdot \sigma$.

The RAT data were extracted using the river mask derived from Landsat imagery at all locations where the river width was more than $80 \mathrm{~m}$. Smaller rivers where many RAT points with high sigma 0 values were observed were also considered.

Except for the highly controlled flows in reaches downstream of reservoirs, rivers in the Zambezi show a strong seasonal signal. This was exploited for outlier removal by splitting the time-series into low- and high-flow series based on the month of the measurement. High- and low-flow months for each VS were determined as follows: for measurements taken on month $\mathrm{N}$, the number of altimeter values below and above the average observed at the station were compared. Months with a majority of values above average were classified as wet and months with a majority of values below average as dry. The previously described outlier removal was then applied to the wet and dry time series separately.

Where more than one data point per satellite pass was available after the selection steps described above, a weighted average of the heights recorded for the same pass was computed. The weights were chosen based on the retracker used to process the data point, with higher weights being attributed to those corresponding to water waveform shapes, i.e. retrackers 5, 8 and 10 (Berry et al., 1997). Retrackers 5, 8 and 10 were given weights of 2, 2 and 4, respectively, and all other retrackers were given weights of 1 .

\subsection{Virtual station quality control}

In order to assess the quality of individual virtual stations and estimate the errors, in situ data were used when available. Data were obtained from the Zambian Department of Water Affairs (DWA) and the Global Runoff Data Centre (GRDC). The stations from the GRDC dataset contain either monthly or daily flow data. Stations in the DWA dataset have either daily water levels or both daily water levels and flows. There are 98 GRDC stations in the Zambezi River basin, of which only 34 have data up to the years 2000 (the latest reported year for one station being 2006). More station data were available in Zambia thanks to the DWA dataset in which more stations and longer time series are reported, though large gaps are present in most station time series.

For virtual stations where an in situ station was available along the same stretch of river with no or little water input from tributaries between the virtual station and in situ station, quality was assessed by calculating the RMSE between the altimetry and in situ datasets.

Some of the altimetry stations were located up to $200 \mathrm{~km}$ from the nearest gauge and the wave celerity had to be taken into account. This was done by finding the delay which maximized the correlation (CC) between the in situ and altimetry datasets. The correlation between the altimetry data and the in situ data were calculated as follows:

$$
\mathrm{CC}(d)=\frac{\frac{1}{n} \cdot \sum_{i=1}^{n}\left(\left[h\left(t_{i}\right)-\bar{h}\right] \cdot\left[y\left(t_{i}+d\right)-\bar{y}\right]\right)}{\sqrt{\frac{1}{n} \cdot \sum_{i=1}^{n}\left[h\left(t_{i}\right)-\bar{h}\right]^{2}} \cdot \sqrt{\frac{1}{n} \cdot \sum_{i=1}^{n}\left[y\left(t_{i}+d\right)-\bar{y}\right]^{2}}}
$$

where $n$ is the number of coincident measurements, $h$ is the altimetry derived water level, $y$ is the in situ measured water level, $d$ is the delay in days, and the overline denotes the average of a series.

Flow cross-sectional area typically varies on short spatial scales and it is therefore not expected to reach a perfect fit between measured and altimetry derived values.

In the case where inflow from tributaries is negligible between the two measurement points and assuming negligible lateral inflow, conservation of flow was assumed along the reach:

$Q_{1(t=t 1)}=Q_{2(t=t 1+d)}$.

With the kinematic wave approximation and considering a wide river (a river is wide if its width is more than 10 times the depth) yields (Dingman, 2002): 
$\frac{B_{1} \cdot Y_{1}^{5 / 3}}{n_{1}} \cdot \sqrt{S_{1}}=\frac{B_{2} \cdot Y_{2}^{5 / 3}}{n_{2}} \cdot \sqrt{S_{2}}$

where $B$ is the water-surface width [m], $Y$ is the average depth [m], $S$ is the channel bed slope and $n$ is Manning's roughness $\left[\mathrm{s} \mathrm{m}^{-1 / 3}\right]$. Assuming that bed slope and Manning's roughness are constant in time at each location, the equation can be rewritten as:

$Y_{1}=C \cdot\left(\frac{B_{2}}{B_{1}}\right)^{3 / 5} \cdot Y_{2}$

where $C$ is a constant which depends on the slope and roughness at each location. At each location, the depth $Y$ can be written as $Y=h+a$ where $h$ is the water level and $a$ is a reference depth, and assuming a time invariant width ratio, we get:

$h_{1(t=t 1)}=\alpha \cdot h_{2(t=t 1+d)}+\beta$,

where $\alpha$ and $\beta$ are fitting parameters which were determined by fitting the amplitude of the time series at the two locations such that the 10th and 90th percentiles for the two series were equal.

The RMSE for the amplitude adjusted and non-adjusted time series were then computed to assess the virtual station's quality:

RMSE $_{\text {amplitude adjusted }}=\sqrt{\frac{\sum_{1}^{n}\left(h_{1(t=t 1)}-\left(\alpha \cdot h_{2(t=t 1+d)}+\beta\right)\right)^{2}}{n}}$

RMSE $=\sqrt{\frac{\sum_{1}^{n}\left(h_{1(t=t 1)}-h_{2(t=t 1+d)}-\left(\overline{h_{1}}-\overline{h_{2}}\right)\right)^{2}}{n}}$

The in situ and altimetry datasets have a different datum which was assumed to be equal to the difference in the mean of the time series and had to be taken into account in cases without amplitude adjustment (Eq. 7). The averages of the time series were therefore subtracted from the measured values.

\subsection{Discharge computation}

In order to assess the potential over the whole Zambezi basin, discharge was computed in different ways, depending on data availability at different virtual stations. The dataavailability categories chosen were the following: VSs with available in situ rating-curves, VSs which were visited during a field campaign where river cross sections and one leveldischarge pair were measured, and VSs with only past or average monthly flows available on the reach or at the outlet of the subbasin. Due to the coarse temporal and spatial resolutions considered in this study and the absence of looped rating curves in the in situ data, the kinematic wave approximation was assumed valid for all discharge computations.

\subsubsection{Method 1 - in situ rating curves}

For virtual stations which coincide with an in situ gauging station, the rating curve from the existing station was used directly. As the in situ and altimetry levels do not have a common height reference, the altimetry dataset was shifted by the difference between the in situ and altimetric means.

The in situ rating curves are power laws of the form:

$Q=a \cdot(h-c)^{b}$,

where $Q$ is the discharge $\left[\mathrm{m}^{3} \mathrm{~s}^{-1}\right], h$ the water level [m], and $a, b$ and $c$ are fitting parameters which were obtained from the DWA database.

It is also possible to build rating curves based on coincident altimetry and in situ flow measurements. However, this method was not applied due to the few coincident points available at the VSs.

\subsubsection{Method 2 - field data}

Where no rating curves are available, a common method to compute flow from the physical characteristics of an open channel is to apply Manning's equation (Chow et al., 1988). The major drawback of Manning's equation is the need for the roughness coefficient, which is difficult to determine. The method presented here uses measurements from one field visit to a VS to get around the roughness coefficient issue.

Over the months of May and June 2010, a field campaign was carried out in the Zambian part of the ZRB and 13 virtual stations were visited. The selection criteria of virtual stations to visit were based on accessibility, river width and proximity to a monitoring station.

For each virtual station, the cross section and flow were measured at one or two locations (as the crossing area between the ground track and the river can be up to a few kilometers wide). This was done using a tagline, weight and propeller (USGS Type AA-MH current meter) for narrow rivers (up to $120 \mathrm{~m}$ wide) and an Acoustic Doppler Current Profiler (ADCP, RiverRay, Teledyne RD Instruments) for wide rivers. With the tagline method, depth was sampled every 5 to $10 \mathrm{~m}$ and velocity measurements were taken at 0.8 and 0.2 times the total depth at each point. The velocities were then averaged and integrated over the cross sectional area to obtain discharge (see full description of the velocity area method in Dingman, 2002).

In order to develop a rating curve using only measured quantities, Manning's equation was applied (Dingman, 2002):

$Q=\frac{A^{5 / 3}}{P^{2 / 3} \cdot n} \cdot \sqrt{S_{\mathrm{f}}}$,

where $Q$ is the river discharge $\left[\mathrm{m}^{3} \mathrm{~s}^{-1}\right], A$ is the cross sectional area $\left[\mathrm{m}^{2}\right], P$ is the wetted perimeter $[\mathrm{m}], n$ is Manning's roughness $\left[\mathrm{s} \mathrm{m}^{-1 / 3}\right]$ which is assumed constant, and 


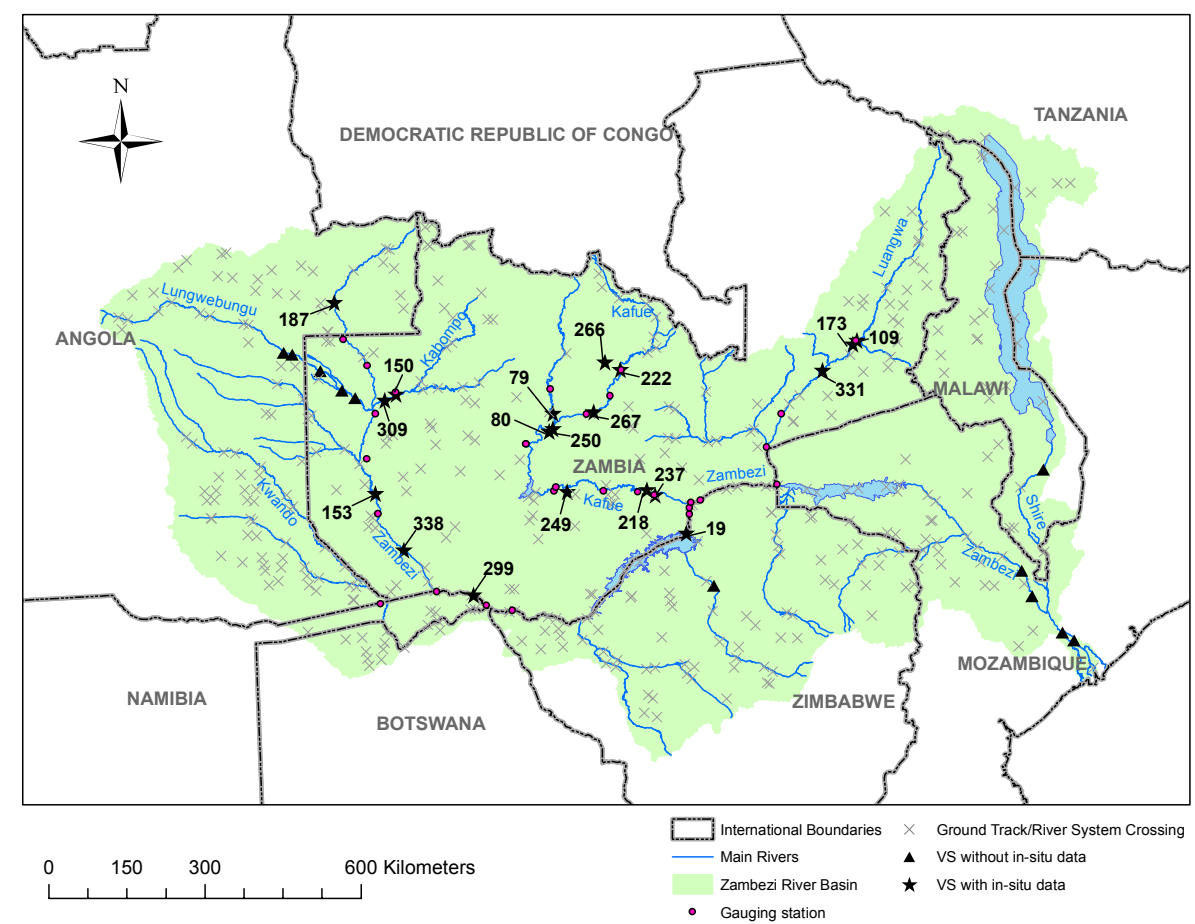

Fig. 1. Location of the virtual stations and monitoring stations with data past the year 2002 in the basin.

$S_{\mathrm{f}}$ is the friction slope which is equal to the bed slope $S_{0}$ in the kinematic wave approximation (Chow et al., 1988). At the time of measurement we have:

$Q_{\mathrm{m}}=\frac{A_{\mathrm{m}}^{5 / 3}}{P_{\mathrm{m}}^{2 / 3} \cdot n} \cdot \sqrt{S_{0}}$,

where the " $m$ " index indicates values measured in the field. Manning's equation can then be rewritten as:

$Q=Q_{\mathrm{m}} \cdot\left(\frac{A}{A_{\mathrm{m}}}\right)^{5 / 3} \cdot\left(\frac{P_{\mathrm{m}}}{P}\right)^{2 / 3}$.

The cross section being known, $A$ and $P$ can be exclusively expressed as functions of water depth. The altimetry to depth conversion is done by acquiring the altimetry water level on the day closest to the day of measurement and using it as a reference.

\subsubsection{Method 3 - historical flow data}

Dingman and Sharma (1997) showed that for a wide range of rivers, a good estimate of discharge can be obtained by applying the following rating curve:

$Q=1.564 \cdot A^{1.173} \cdot R^{0.4} \cdot S^{-0.0543 \cdot \log 10(S)}$,

where $A$ is the cross-sectional area $\left[\mathrm{m}^{2}\right], R$ is the hydraulic radius [m] and $S$ is the water-surface slope. This equation has the advantage of relying only on morphological characteristics of the river. However, there is no remote sensing technique capable of measuring river depth, which is needed to obtain cross-sections. Therefore the use of this equation implies making assumptions on channel geometry. The assumption made here was that of a rectangular cross section. Channel width was read from Landsat imagery by dividing the channel area by the channel length. In the kinematic wave approximation, the water surface slope is equal to the bed slope (Chow et al., 1988). In order to determine the bed slope, elevation was extracted from the Shuttle Radar Topography Mission (SRTM) data along a $20 \mathrm{~km}$ stretch of river around the VS and the slope determined by linear regression.

For the conversion of altimetry measurements to depth, a reference depth was derived. For many reaches in the Zambezi River basin, the only type of data available is monthly discharge data covering all or part of the time period between 1950 and 1980 from GRDC stations or average monthly discharges for the major subbasins. These data were exploited based on the observation that inter-annual flow variations in uncontrolled reaches are low in the dry months. The average in situ flow value for the driest month was calculated from the dataset, and the flow Eq. (12) was solved for $d$. Rewriting the flow equation in terms of channel depth and width yields:

$$
\begin{aligned}
Q_{\text {low }}= & 1.564 \cdot\left(W \cdot d_{\text {low }}\right)^{1.173} \cdot\left(\frac{W \cdot d_{\text {low }}}{W+2 \cdot d_{\text {low }}}\right)^{0.4} \\
& \cdot S_{0}^{-0.0543 \cdot \log 10\left(S_{0}\right)}
\end{aligned}
$$

where $Q_{\text {low }}\left[\mathrm{m}^{3} \mathrm{~s}^{-1}\right]$ is the average flow for the driest month of the year and $d_{\text {low }}[\mathrm{m}]$ is the depth associated to this flow 
Table 1. RMSE, distance to gauge and high flow channel width. (d) indicates the gauge is located downstream, and (u) upstream from the virtual station. The index "a" after the channel width value indicates the virtual station is located in a channel with a floodplain, the index "b" indicates the presence of pools adjacent to the channel and the index "c" indicates a braided river channel.

\begin{tabular}{|c|c|c|c|c|c|c|c|}
\hline \multirow[t]{2}{*}{ VS } & \multicolumn{2}{|c|}{$\begin{array}{l}\text { RMSE [m] } \\
\text { Amplitude } \\
\text { adjusted? }\end{array}$} & \multicolumn{2}{|c|}{$\begin{array}{l}\text { RMSE as \% of } \\
\text { total amplitude } \\
\text { Amplitude } \\
\text { adjusted? }\end{array}$} & \multirow[t]{2}{*}{$\begin{array}{l}\text { No. of } \\
\text { points of } \\
\text { comparison }\end{array}$} & \multirow[t]{2}{*}{$\begin{array}{l}\text { Approx. } \\
\text { distance to } \\
\text { gauge }[\mathrm{km}]\end{array}$} & \multirow[t]{2}{*}{$\begin{array}{l}\text { Approx. } \\
\text { channel } \\
\text { width }[\mathrm{m}]\end{array}$} \\
\hline & No & Yes & No & Yes & & & \\
\hline 19 & 0.39 & 0.54 & 21.3 & 29.8 & 23 & $10(d)$ & 400 \\
\hline 79 & 0.97 & 0.56 & 38.1 & 21.9 & 27 & $90(\mathrm{u})$ & 85 \\
\hline 80 & 1.04 & 0.37 & 39.8 & 14.0 & 38 & $105(\mathrm{~d})$ & 180 \\
\hline 109 & 0.38 & 0.38 & 6.5 & 6.5 & 10 & 0 & 140 \\
\hline 150 & 0.34 & 0.39 & 11.5 & 13.1 & 14 & 0 & 130 \\
\hline 153 & 0.37 & 0.47 & 9.9 & 10 & 36 & 45 (d) & $260^{\mathrm{a}}$ \\
\hline 173 & 0.63 & 0.68 & 18.3 & 19.8 & 10 & $20(\mathrm{u})$ & 180 \\
\hline 187 & 1.01 & 0.47 & 20.9 & 9.7 & 28 & 95 (d) & 380 \\
\hline 218 & 0.80 & 0.46 & 35.8 & 20.3 & 37 & $15(d)$ & $230^{\mathrm{b}}$ \\
\hline 222 & 0.37 & 0.37 & 10.3 & 10.4 & 6 & 0 & 100 \\
\hline 237 & 0.72 & 0.75 & 25.1 & 23.7 & 35 & 0 & 310 \\
\hline 249 & 0.46 & 0.47 & 9.9 & 9.6 & 41 & $30(\mathrm{u})$ & $170^{\mathrm{c}}$ \\
\hline 250 & 0.85 & 0.60 & 30 & 21 & 34 & $115(d)$ & 230 \\
\hline 266 & 0.60 & 0.46 & 23.2 & 17.7 & 13 & $40(d)$ & $40^{\mathrm{a}}$ \\
\hline 267 & 0.27 & 0.24 & 8.3 & 7.6 & 15 & $15(d)$ & 130 \\
\hline 296 & 0.83 & 0.83 & 16.4 & 16.5 & 6 & $180(\mathrm{~d})$ & 250 \\
\hline 299 & 0.74 & 1.56 & 11 & 23 & 21 & $80(\mathrm{u})$ & $250^{\mathrm{a}}$ \\
\hline 309 & 0.36 & 0.32 & 14.4 & 8.6 & 11 & $25(\mathrm{u})$ & 120 \\
\hline 331 & 1.07 & 1.06 & 14.4 & 12.4 & 29 & $200(d)$ & 350 \\
\hline 338 & 0.79 & 0.61 & 19.3 & 15 & 8 & $110(\mathrm{~d})$ & 300 \\
\hline Mean & 0.64 & 0.58 & 19.2 & 15.5 & 22 & & \\
\hline
\end{tabular}

value. The average altimetry height for the driest month, $h_{\text {low }}$, was then extracted and the altimetry to depth conversion carried out as follows:

$d=h-\left(h_{\text {low }}-d_{\text {low }}\right)$.

\subsection{Uncertainty analysis}

For each of the discharge computation methods presented, the magnitude of the uncertainties in the measured quantities was estimated and their impact on the final discharge estimate analyzed using Monte Carlo simulations. For each method, 1000 runs were carried out by randomly sampling the uncertain quantities from normal distributions where the measured value was taken as the mean and the standard deviations of the distributions were determined as described in the next paragraphs. The in situ rating curves were used as the benchmark for quality assessment and therefore not considered uncertain.

For all three methods, the standard deviation of the altimetric stage was taken as the RMSE calculated in the nonadjusted case (see Sect. 2.2).

In method 2, for the field tagline measurements, the standard deviations on the measured depths, distances and velocities for sampling were determined to be $5 \mathrm{~cm}, 50 \mathrm{~cm}$ and $5 \mathrm{~mm} \mathrm{~s}^{-1}$, respectively, based on the field procedure. For the ADCP measurements, the standard deviations on the measured flow and cross section are outputs of the measurement and were directly used as such.

For method 3, uncertainty on the measured slope was determined from the fit of the linear regression from the SRTM data (see Sect. 2.3.3), and uncertainty on maximum width was determined to be $20 \%$ of the measured width. The standard deviation on the low flow value was computed from the sample of average monthly flows available for the driest month at each in situ station.

\section{Results}

\subsection{In situ and altimetric river level}

The satellite ground track was found to cross the river network in the Zambezi at 423 points. These were located on rivers, lakes and floodplains. After elimination of time series with too few data points, too many outliers or unrealistically high annual level variations, 31 virtual stations were identified as useable. Of these, 20 were located on the same stretch 

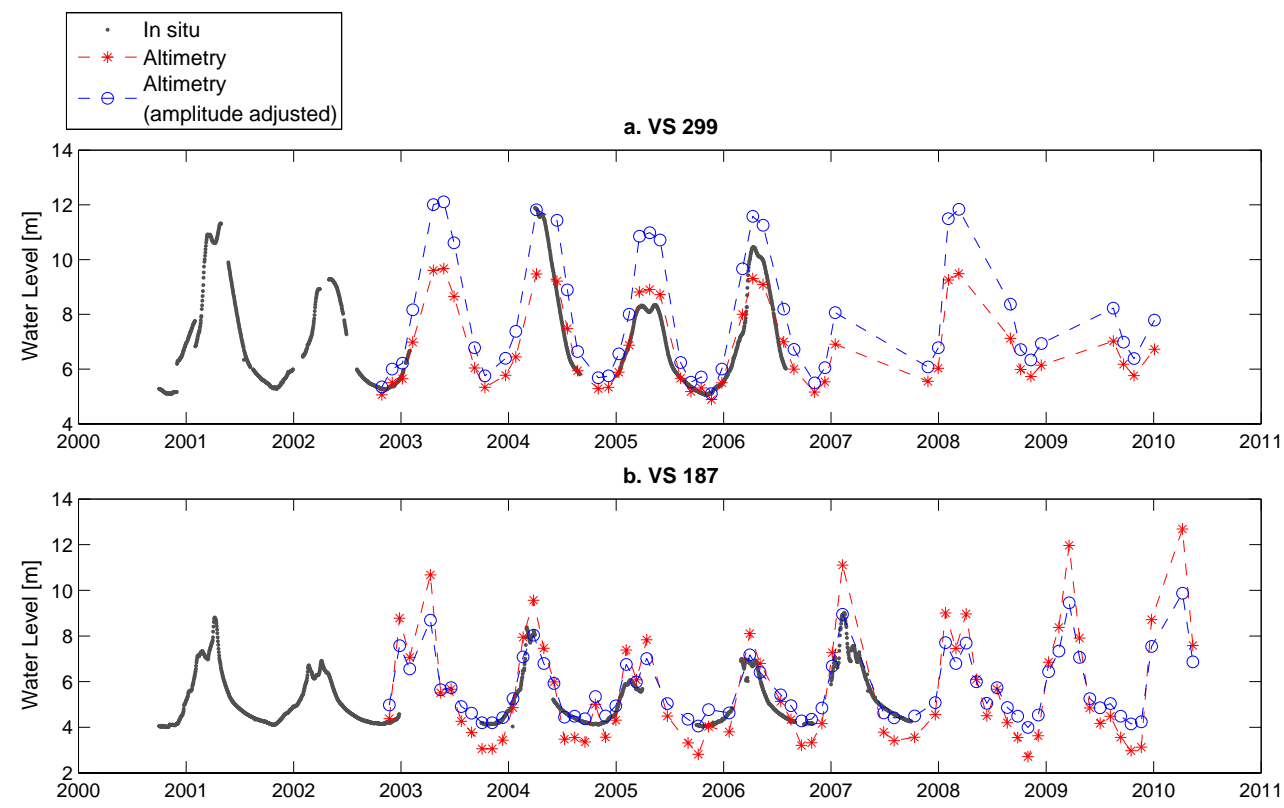

Fig. 2. Comparison of altimetry derived water levels and in situ water levels for VS 299 (a) and VS 187 (b).

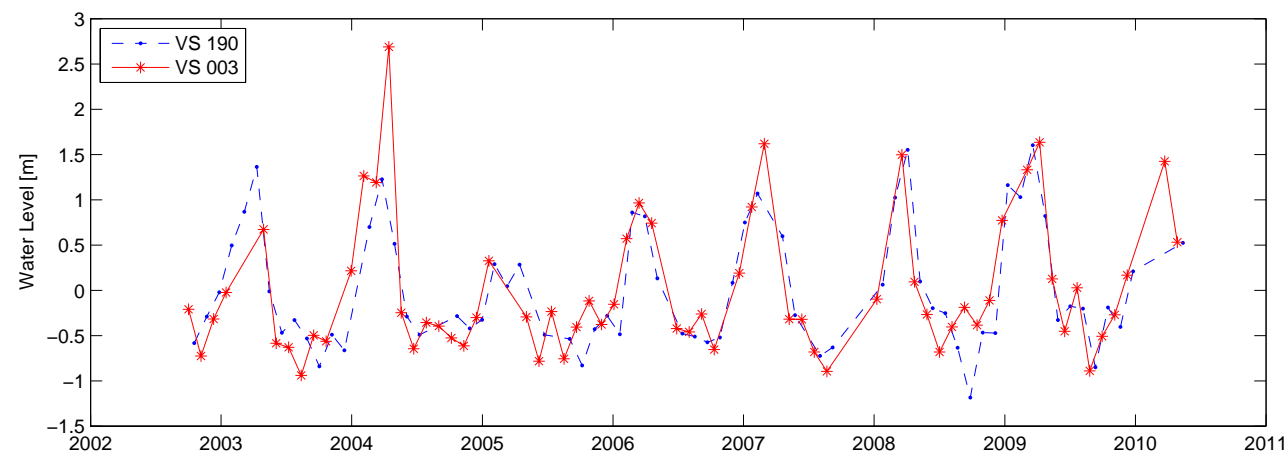

Fig. 3. Data from altimetry VS 003 (70 m wide) and VS 190 ( 75 m wide) located on the Lungwebungu River in North Western Zambia.

as a gauging station with recent level and/or flow data. The locations of the VSs and useable gauging stations are presented in Fig. 1.

Comparing VS and in situ data yielded RMSE values between 0.34 and $0.72 \mathrm{~m}$, which corresponds to 6.5 to $25.1 \%$ of total amplitude for VSs coinciding with gauge locations. For VSs where the gauge was located further on the same reach, RMSE values between $0.27 \mathrm{~m}$ and $1.07 \mathrm{~m}$ (or between 8.3 and $39.8 \%$ of amplitude) without amplitude adjustment and from $0.24 \mathrm{~m}$ to $1.56 \mathrm{~m}$ RMSE (or between 7.6 and $29.8 \%$ of amplitude) with amplitude adjustment were found (Table 1).

In most cases where the gauge was located far from the virtual station, the amplitude adjustment improved the RMSE. However this was not always the case, in part because of the time resolution of the altimetry dataset and the uncertain estimation of the delay between gauge and virtual station. With one data point every 35 days, the altimetry dataset may miss important peaks of short duration, leading to an erroneous rescaling of the altimetry data. Figure $2 \mathrm{a}$ shows an example of this problem occurring at VS 299.

Figure $2 b$ however shows an example where using the amplitude adjusted altimetry dataset allowed for a better quality classification: the unfitted RMSE of $1.01 \mathrm{~m}$ for VS 187 (see Table 1) would classify the virtual station as of poor quality while Fig. $2 b$ justified the classification of the virtual station as "good".

The amplitude adjusted and non-adjusted RMSE values therefore needed to be combined in the classification of virtual stations and visual inspection was necessary in some cases. For VSs located far from the gauging station used for comparison, the RMSE values were not directly used for the classification, but rather as indicators, as the assumption of negligible inflow between VS and gauge (see Sect. 2.2) was no longer valid for some of the distances considered.

In order to classify virtual stations not located near gauging stations, quality was assessed by visually comparing data 
Table 2. Results for discharge calculations using method 1 .

\begin{tabular}{llllllll}
\hline $\begin{array}{l}\text { VS } \\
\text { Number }\end{array}$ & $\begin{array}{l}\text { RMSE } \\
{\left[\mathrm{m}^{3} \mathrm{~s}^{-1}\right]}\end{array}$ & $\begin{array}{l}\text { RMSE \% } \\
\text { of mean } \\
\text { amplitude }\end{array}$ & $\begin{array}{l}\text { STD } \\
{\left[\mathrm{m}^{3} \mathrm{~s}^{-1}\right]}\end{array}$ & $\begin{array}{l}\text { STD \% } \\
\text { of mean } \\
\text { amplitude }\end{array}$ & $\begin{array}{l}\text { No. of } \\
\text { points of } \\
\text { comparison }\end{array}$ & $\begin{array}{l}\text { Historical mean } \\
\text { amplitude } \\
{\left[\mathrm{m}^{3} \mathrm{~s}-1\right]}\end{array}$ & $\begin{array}{l}\text { Historical } \\
\text { mean flow } \\
{\left[\mathrm{m}^{3} \mathrm{~s}^{-1}\right]}\end{array}$ \\
\hline 109 & 69.4 & 7.2 & 64.6 & 6.7 & 8 & 957.8 & 181.6 \\
150 & 48.5 & 6.1 & 57.1 & 7.2 & 14 & 796.0 & 242.2 \\
222 & 19.9 & 4.5 & 25.4 & 5.7 & 6 & 445.6 & 144.8 \\
237 & 299.4 & 44.1 & 331.2 & 48.9 & 35 & 677.3 & 1030.3 \\
\hline
\end{tabular}

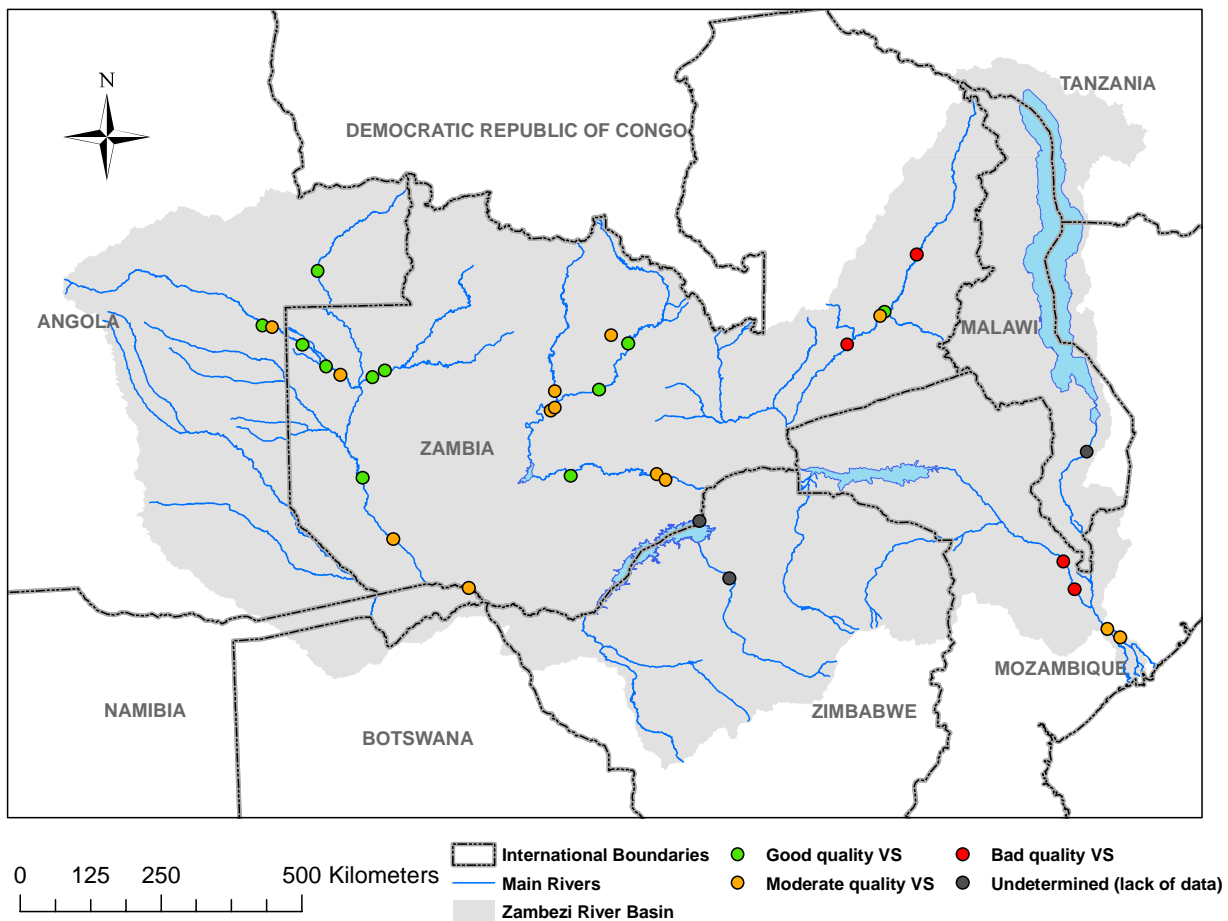

Fig. 4. VS location and quality in the Zambezi River basin.

from altimetry virtual stations located along the same reach. Figure 3 shows an example where the virtual stations were classified as "good". The mean of each time series was subtracted from the measured levels to account for the different elevations at the two VSs.

This method however was not used in highly controlled reaches, as the comparison of non-simultaneous data points could no longer be carried out due to the high daily (or even sub-daily) flow variations from reservoir releases.

It should be noted that on reaches with highly controlled flows, no good quality virtual stations were identified, partly due to the fact that the outlier removal approach used is more efficient for time-series with a strong seasonal signal (see Sect. 2.1). However, even in the event of a good quality virtual station being located on such a reach, the utility of one measurement point every 35 days in an environment with very high daily variations in flow would be limited.
Figure 4 shows the classification based on the criteria described above. The label "good" corresponds to a VS with an expected error of less than $40 \mathrm{~cm}$, "moderate" to a VS with an expected error of less than $70 \mathrm{~cm}$, and "bad" to a VS with an expected error of more than $70 \mathrm{~cm}$. Due to lack of both in situ and neighboring VS, some of the VSs could not be classified.

\subsection{Discharge}

Discharge estimates were carried out for all of the analyzed virtual stations with the three methods described previously where the necessary data were available. For all methods, the in situ measured discharge was used as the benchmark for the discharge prediction based on altimetry. In this section, results are presented both in terms of accuracy and precision. The RMSE values present the expected deviation of the mean modeled discharge relative to the in situ measured flows and 
Table 3. Results for discharge calculations using method 2.

\begin{tabular}{llllllll}
\hline $\begin{array}{l}\text { VS } \\
\text { Number }\end{array}$ & $\begin{array}{l}\text { RMSE } \\
{\left[\mathrm{m}^{3} \mathrm{~s}^{-1}\right]}\end{array}$ & $\begin{array}{l}\text { RMSE } \% \\
\text { of mean } \\
\text { amplitude }\end{array}$ & $\begin{array}{l}\text { STD } \\
{\left[\mathrm{m}^{3} \mathrm{~s}^{-1}\right]}\end{array}$ & $\begin{array}{l}\text { STD \% } \\
\text { of mean } \\
\text { amplitude }\end{array}$ & $\begin{array}{l}\text { No. of } \\
\text { points of } \\
\text { comparison }\end{array}$ & $\begin{array}{l}\text { Historical mean } \\
\text { amplitude } \\
{\left[\mathrm{m}^{3} \mathrm{~s}^{-1}\right]}\end{array}$ & $\begin{array}{l}\text { Historical } \\
\text { mean flow } \\
{\left[\mathrm{m}^{3} \mathrm{~s}^{-1}\right]}\end{array}$ \\
\hline 150 & 59.9 & 7.5 & 69.5 & 8.7 & 14 & 796.0 & 242.2 \\
222 & 49.8 & 11.2 & 42.2 & 9.5 & 6 & 445.6 & 144.8 \\
309 & 42.9 & 5.4 & 54.5 & 6.8 & 11 & 796.0 & 242.2 \\
\hline
\end{tabular}

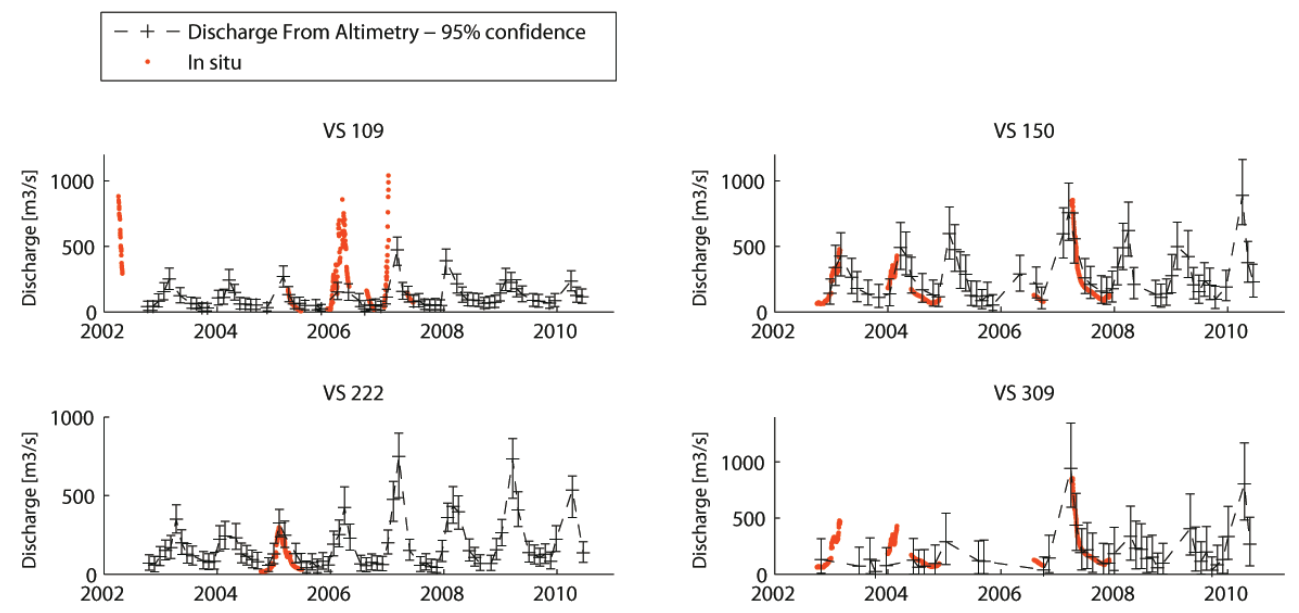

Fig. 5. Comparison of measured and simulated discharge from altimetry and field measured cross section and flow with $95 \%$ confidence intervals.

the standard deviations (std) present the spread between the model runs for each method. In order to show the significance of these errors, they are also presented as $\%$ of historical in situ annual amplitude.

Method 1, using in situ rating curves, was only applied to the four virtual stations located at an in situ rating curve. For the virtual stations classified as "good", the std on the discharge calculations were found to be between 25.4 and $64.6 \mathrm{~m}^{3} \mathrm{~s}^{-1}$ with an RMSE ranging from 19.9 to $69.4 \mathrm{~m}^{3} \mathrm{~s}^{-1}$ relative to the in situ data which corresponds to 4.5 to $7.2 \%$ of the mean annual amplitude (Table 2).

Method 2 was applied to 4 of the 5 selected virtual stations where field data were collected. The 5th, VS 237, could not be used because no data were collected by the satellite during the pass corresponding to the time of the field measurement.

The field-derived (method 2) and in situ discharge timeseries were first inspected. Good agreement was found for VS 150, VS 222 and VS 309. At VS 109 the field rating curve was found to significantly underestimate discharge (Fig. 5).

At the gauge near VS 109, a second rating curve based on pre-1984 in situ measurements was also available (dashed grey line in Fig. 6) and was found to be much closer to our field-derived rating curve.

The shape of the field rating curve depends on two major variables: the measured flow on the day of the field visit and the value of the altimetry height on that day. With the

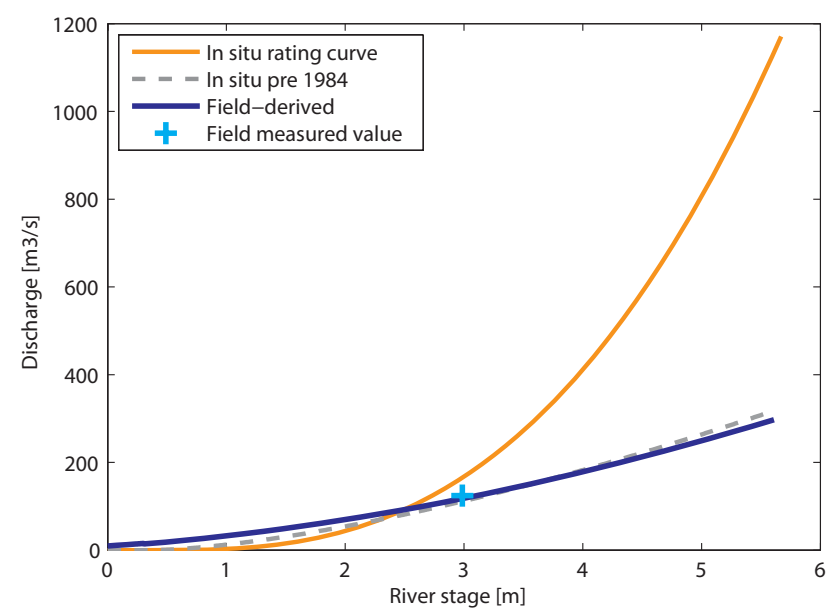

Fig. 6. In situ and field rating curves at VS 109.

available data, we were not able to determine whether the measurements were faulty or which in situ rating-curve produced the more accurate results and VS 109 was therefore left out for further analysis of method 2 . It should also be noted that the in situ rating curves at VS 109 are available only to $5.61 \mathrm{~m}$, while the maximum in situ stage measured is $8.35 \mathrm{~m}$ and no comparisons could therefore be carried out at high flow levels. 
Table 4. In situ average low monthly flow values and standard deviations.

\begin{tabular}{lrrrrrr}
\hline $\begin{array}{l}\text { VS } \\
\text { Number }\end{array}$ & $\begin{array}{r}Q \text { low } \\
{\left[\mathrm{m}^{3} \mathrm{~s}^{-1}\right]}\end{array}$ & $\begin{array}{r}\text { STD } Q \\
\text { low } \\
{\left[\mathrm{m}^{3} \mathrm{~s}^{-1}\right]}\end{array}$ & $\begin{array}{r}\text { STD \% } \\
\text { of mean } \\
\text { amplitude }\end{array}$ & $\begin{array}{r}\text { Years of } \\
\text { data }\end{array}$ & $\begin{array}{r}\text { Historical mean } \\
\text { amplitude } \\
{\left[\mathrm{m}^{3} \mathrm{~s}^{-1}\right]}\end{array}$ & $\begin{array}{r}\text { Historical } \\
\text { mean flow } \\
{\left[\mathrm{m}^{3} \mathrm{~s}^{-1}\right]}\end{array}$ \\
\hline 79 & 27.4 & 7.42 & 2.9 & 39 & 256.1 & 68.4 \\
109 & 27.0 & 33.6 & 3.5 & 9 & 957.8 & 181.6 \\
150 & 66.6 & 20.6 & 2.6 & 39 & 796.0 & 242.2 \\
153 & 244.7 & 41.0 & 1.9 & 11 & 2106.5 & 905.1 \\
173 & 27.0 & 33.6 & 3.5 & 9 & 957.8 & 181.6 \\
222 & 23.4 & 9.2 & 2.1 & 37 & 445.6 & 144.8 \\
266 & 6.1 & 4.0 & 9.3 & 17 & 43.2 & 17.9 \\
267 & 28.6 & 13.9 & 3.3 & 36 & 418.6 & 158.5 \\
299 & 367 & 94.1 & 2.8 & 37 & 3383.3 & 2720.8 \\
309 & 66.7 & 20.0 & 2.5 & 39 & 796.0 & 242.2 \\
\hline
\end{tabular}

Table 5. Results for discharge calculations using method 3. Bold entries signal VS location not coinciding with that of the gauge used for comparison.

\begin{tabular}{lrrrrrrr}
\hline $\begin{array}{l}\text { VS } \\
\text { Number }\end{array}$ & $\begin{array}{r}\text { RMSE } \\
{\left[\mathrm{m}^{3} \mathrm{~s}^{-1}\right]}\end{array}$ & $\begin{array}{r}\text { RMSE \% of } \\
\text { mean } \\
\text { amplitude }\end{array}$ & $\begin{array}{r}\text { STD } \\
{\left[\mathrm{m}^{3} \mathrm{~s}^{-1}\right]}\end{array}$ & $\begin{array}{r}\text { STD as \% } \\
\text { of mean } \\
\text { amplitude }\end{array}$ & $\begin{array}{r}\text { Distance } \\
\text { to gauge } \\
{[\mathrm{km}]}\end{array}$ & $\begin{array}{r}\text { Historical mean } \\
\text { amplitude } \\
{\left[\mathrm{m}^{3} \mathrm{~s}^{-1}\right]}\end{array}$ & $\begin{array}{r}\text { Historical } \\
\text { mean flow } \\
{\left[\mathrm{m}^{3} \mathrm{~s}^{-1}\right]}\end{array}$ \\
\hline $\mathbf{7 9}$ & $\mathbf{8 8 . 9}$ & $\mathbf{3 4 . 7}$ & $\mathbf{1 2 1 . 2}$ & $\mathbf{4 7 . 3}$ & $\mathbf{9 0}$ & 256.1 & 68.4 \\
109 & 132.5 & 13.8 & 113.5 & 11.8 & 0 & 957.8 & 181.6 \\
150 & 55.2 & 6.9 & 70.6 & 8.9 & 0 & 796.0 & 242.2 \\
$\mathbf{1 7 3}$ & $\mathbf{2 9 7 . 4}$ & $\mathbf{3 1 . 1}$ & $\mathbf{1 5 4 . 8}$ & $\mathbf{1 6 . 2}$ & $\mathbf{2 0}$ & 957.8 & 181.6 \\
222 & 54.0 & 12.1 & 57.9 & 13.0 & 0 & 445.6 & 144.8 \\
$\mathbf{2 6 6}$ & $\mathbf{3 3 . 0}$ & $\mathbf{7 6 . 3}$ & $\mathbf{2 4 . 1}$ & $\mathbf{5 5 . 7}$ & $\mathbf{4 0}$ & 43.2 & 17.9 \\
$\mathbf{2 6 7}$ & $\mathbf{8 2 . 8}$ & $\mathbf{1 9 . 8}$ & $\mathbf{6 1 . 8}$ & $\mathbf{1 4 . 8}$ & $\mathbf{1 5}$ & 418.6 & 158.5 \\
$\mathbf{2 9 9}$ & $\mathbf{5 3 8 . 0}$ & $\mathbf{1 5 . 9}$ & $\mathbf{4 7 8 . 2}$ & $\mathbf{1 4 . 1}$ & $\mathbf{8 0}$ & 3383.3 & 2720.8 \\
$\mathbf{3 0 9}$ & $\mathbf{4 7 . 3}$ & $\mathbf{5 . 9}$ & $\mathbf{7 4 . 2}$ & $\mathbf{9 . 3}$ & $\mathbf{2 5}$ & 796.0 & 242.2 \\
\hline
\end{tabular}

For the remaining $3 \mathrm{VSs}$, RMSE values ranging from 42.9 to $59.9 \mathrm{~m}^{3} \mathrm{~s}^{-1}$ relative to the in situ data were found, which corresponds to 5.4 to $11.2 \%$ of the mean annual amplitude and with standard deviations between 6.8 and $9.5 \%$ of the mean annual amplitude value (Table 3 ).

In order to apply method 3, using historical data as lowflow calibration, the values of average minimum monthly flow and the standard deviation were calculated from the available in situ data. For operational gauges, the time series was used up to the year 2000. While the std on the low flows were typically found to represent a high percentage of the low flow values (from $16 \%$ to $120 \%$ of the low flow values), the impact of this uncertainty on the std of flow estimates was found to be relatively low with values ranging from $1.9 \%$ to $9.3 \%$ of the average annual amplitude (Table 4 ).

Applying method 3 yielded RMSE values on computed flows between 54.0 and $132.5 \mathrm{~m}^{3} \mathrm{~s}^{-1}$ corresponding to 6.9 to $13.8 \%$ of the mean annual amplitude, with std values between 8.9 and $13.0 \%$ of the mean annual amplitude for VSs located at the same place as a gauge (Table 5). The method was also applied to VSs up to $90 \mathrm{~km}$ from the nearest gauge yielding RMSE values between 33.0 and
$538.0 \mathrm{~m}^{3} \mathrm{~s}^{-1}$, which correspond to 5.9 to $76.3 \%$ of mean annual amplitude with std values between 9.3 and $55.7 \%$ of the mean annual amplitude. It should be noted that these flow estimates are not meant as estimates at the gauge locations but at the VS locations.

\section{Discussion}

While previous river altimetry studies focused on wide rivers (from $200 \mathrm{~m}$ to a few $\mathrm{km}$ wide), using retracked altimetry and a detailed river mask enabled us to extract accurate stage measurements for rivers down to $80 \mathrm{~m}$ widths and useable levels were also extracted for one $40 \mathrm{~m}$ wide river. Using an outlier removal strategy based only on the seasonality and spread of the altimetry time-series itself, RMSE values of between 0.32 and $0.72 \mathrm{~m}$ were obtained for VS locations coinciding with a gauging station. These values are comparable to the 0.44 to $0.76 \mathrm{~m}$ reported by Birkinshaw et al. (2010) in their study of the Mekong River using the same retracking methodology, though the Mekong study concerned wider rivers (over $450 \mathrm{~m}$ wide). 
For the rivers studied, the RMSE of 0.34 to $0.72 \mathrm{~m}$ on stage translated to errors from 5.7 to $48.9 \%$ of average yearly amplitude using the in situ rating curve. For the VS classified as "good", the range was reduced to 5.7 to $7.2 \%$ of average yearly amplitude, which is an acceptable level of error considering the errors expected for rating-curve derived discharge measurements.

For cases where no pre-existing rating curves were available, two methods were developed and tested. Both methods relied on obtaining a reference flow/cross section pair either by carrying out field work or by assuming a rectangular channel and using historical low-flow values as a reference.

The method using field data yielded RMSE values between 5.4 and $11.2 \%$ of the average yearly amplitude for three of the VS considered with standard deviations between 6.8 and $9.5 \%$ of the amplitude. These results are comparable to those found using an existing rating curve, which is promising as it implies that any accessible river-ground track crossing of interest can become a virtual flow monitoring station based on one field visit to the site. However, at the last VS, the field-derived rating curve systematically underestimated high flows and further study of the area would be needed in order to establish which rating curve provides the best discharge estimates.

Using the historical flow method to estimate discharge yielded RMSE values between 54.0 and $132.5 \mathrm{~m}^{3} \mathrm{~s}^{-1}$, corresponding to 6.9 to $13.8 \%$ of average annual amplitude at the VSs coinciding with a gauging station. Standard deviations relative to the average annual amplitude were found to be between 8.9 and $13.0 \%$ at these locations. For the VSs not located at a gauge, RMSE values were found to be less than $35 \%$ and std values less than $47.3 \%$ of the average annual amplitude, except for VS 266 where the high errors can be explained by the fact that the river is narrow at that point $(40 \mathrm{~m})$ and the uncertainty on the measured slope from SRTM high. The RMSE values at the other locations showed the possibility of applying this method when the historical flow data record available was from a gauge located in our case up to $90 \mathrm{~km}$ along the same reach as the VS, thereby increasing the number of potential virtual discharge gauging stations.

The advantage of this method is that historical flow data is usually much more readily available than more recent data and averaged monthly flows are data typically found in openly available reports (e.g. The World Bank, 2010), and could therefore be used in such an approach (more detailed datasets are not always made available by the organizations in charge of data collection). One major drawback is the rectangular cross section hypothesis which does not allow for the inclusion of complex river profiles, the flooding of banks, etc. This could be improved by adapting the cross-sectional profile by obtaining time-series of river widths, which can also be obtained from remote sensing imagery. This will in particular be aided by the launch of the Surface Water Ocean Topography (SWOT) mission, which will be dedicated to hydrology and provide measurements of river width and surface slope as well as stage (Durand et al., 2010).

\section{Conclusions}

This study has shown the high potential for stage as well as discharge monitoring in the from radar altimetry Zambezi River basin. Discharge was computed in reaches with varying amounts of available in situ data (method 1) and two other methods were developed which can be applied in many of the world's basins, provided one field visit can be carried out at the VS for the field data method (method 2) or there is the availability of historical flow data and low interannual variability in dry-season flow for the historical flow data method (method 3).

While the 35-day time resolution of Envisat remains insufficient for many applications, it is expected that combining these data with basin-scale hydrological modeling in a data assimilation framework will improve discharge estimates on finer time and spatial scales than the satellite resolution. The advantage of such an approach would be the real-time updating of flows at VS locations as well as at other locations along the same river stretch where the flow data is needed, thereby increasing the value of radar altimetry level data for water managers.

Acknowledgements. The authors would like to thank Danida, Danish Ministry of Foreign Affairs for funding the research presented in this paper (project number 09-043DTU). The authors would also like to thank the Zambian Department of Water Affairs and the Global Runoff Data Centre (GRDC, D-56002 Koblenz, Germany) for providing gauge data as well as Roland Zurbrügg and the ADAPT project for lending the ADCP for the field study and the IWRM Centre at the University of Zambia and Mwiza Muzumara for support during the field study.

Edited by: G. Di Baldassarre

\section{References}

Andreadis, K. M., Clark, E. A., Lettenmaier, D. P., and Alsdorf, D. E.: Prospects for river discharge and depth estimation through assimilation of swath-altimetry into a rasterbased hydrodynamics model, Geophys. Res. Lett., 34, L10403, doi:10.1029/2007GL029721, 2007.

Aubert, D., Loumagne, C., and Oudin, L.: Sequential assimilation of soil moisture and streamflow data in a conceptual rainfallrunoff model, J. Hydrol., 280, 145-161, 2003.

Berry, P. A. M., Jasper, A., and Bracke, H.: Retracking ERS-1 altimeter waveforms overland for topographic height determination: an expert system approach, ESA Sp. Publ., 1, 403-408, 1997.

Berry, P. A. M., Garlick, J. D., Freeman, J. A., and Mathers, E. L.: Global inland water monitoring from multi-mission altimetry, 
Geophys. Res. Lett., 32, L16401, doi:10.1029/2005GL022814, 2005.

Biancamaria, S., Durand, M., Andreadis, K. M., Bates, P. D., Boone, A., Mognard, N. M., Rodriguez, E., Alsdorf, D. E., Lettenmaier, D. P., and Clark, E. A.: Assimilation of virtual wide swath altimetry to improve Arctic river modeling, Remote Sensing of Environment, 115, 373-381, 2011.

Birkett, C. M.: The contribution of TOPEX/POSEIDON to the global monitoring of climatically sensitive lakes, J. Geophys. Res.-Oceans, 100, 25179-25204, 1995.

Birkett, C. M.: Contribution of the TOPEX NASA radar altimeter to the global monitoring of large rivers and wetlands, Water Resour. Res., 34, 1223-1239, 1998.

Birkett, C. M.: Synergistic remote sensing of Lake Chad: Variability of basin inundation, Remote Sens. Environ., 72, 218-236, 2000.

Birkinshaw, S. J., O’Donnell, G. M., Moore, P., Kilsby, C. G., Fowler, H. J., and Berry, P. A. M.: Using satellite altimetry data to augment flow estimation techniques on the Mekong River, Hydrol. Process., 24, 3811-3825, 2010.

Bjerklie, D. M., Dingman, S. L., Vorosmarty, C. J., Bolster, C. H., and Congalton, R. G.: Evaluating the potential for measuring river discharge from space, J. Hydrol., 278, 17-38, 2003.

Calmant, S., Seyler, F., and Cretaux, J. F.: Monitoring Continental Surface Waters by Satellite Altimetry, Surv. Geophys., 29, $247-$ 269, 2008

Chow, V. T., Maidment, D. R., and Mays, L. W.: Applied hydrology, McGraw-Hill series in water resources and environmental engineering, McGraw-Hill, New York, 1988.

Dingman, S. L.: Physical hydrology, Prentice Hall, Upper Saddle River, NJ, 2002.

Dingman, S. L. and Sharma, K. P.: Statistical development and validation of discharge equations for natural channels, J. Hydrol., 199, 13-35, 1997.

Durand, M., Fu, L. L., Lettenmaier, D. P., Alsdorf, D. E., Rodriguez, E., and Esteban-Fernandez, D.: The Surface Water and Ocean Topography Mission: Observing Terrestrial Surface Water and Oceanic Submesoscale Eddies, Proceedings of the Ieee, 98, 766779, 2010

Farr, T. G., Rosen, P. A., Caro, E., Crippen, R., Duren, R., Hensley, S., Kobrick, M., Paller, M., Rodriguez, E., Roth, L., Seal, D., Shaffer, S., Shimada, J., Umland, J., Werner, M., Oskin, M., Burbank, D., and Alsdorf, D.: The shuttle radar topography mission, Rev. Geophys, 45, RG2004, doi:10.1029/2005RG000183, 2007.

Fekete, B. M. and Vörösmarty, C. J.: The current status of global river discharge monitoring and potential new technologies complementing traditional discharge measurements. Proceedings of the PUB Kick-off meeting (Brasilia, 20-22 November 2002), IAHS-AISH P., 309, 129-136, 2007.

Frappart, F., Calmant, S., Cauhope, M., Seyler, F., and Cazenave, A.: Preliminary results of ENVISAT RA-2-derived water levels validation over the Amazon basin, Remote Sens. Environ., 100, 252-264, 2006.

Getirana, A. C. V.: Integrating spatial altimetry data into the automatic calibration of hydrological models, J. Hydrol., 387, 244 $255,2010$.
Getirana, A. C. V., Bonnet, M. P., Calmant, S., Roux, E., Rotunno, O. C., and Mansur, W. J.: Hydrological monitoring of poorly gauged basins based on rainfall-runoff modeling and spatial altimetry, J. Hydrol., 379, 205-219, 2009.

Koblinsky, C. J., Clarke, R. T., Brenner, A. C., and Frey, H.: Measurement of River Level Variations with Satellite Altimetry, Water Resour. Res., 29, 1839-1848, 1993.

Kouraev, A. V., Zakharova, E. A., Samain, O., Mognard, N. M., and Cazenave, A.: Ob' river discharge from TOPEX/Poseidon satellite altimetry (1992-2002), Remote Sens. Environ., 93, 238245, 2004

Leon, J. G., Calmant, S., Seyler, F., Bonnet, M. P., Cauhope, M., Frappart, F., Filizola, N., and Fraizy, P.: Rating curves and estimation of average water depth at the upper Negro River based on satellite altimeter data and modeled discharges, J. Hydrol., 328, 481-496, 2006.

Milzow, C., Krogh, P. E., and Bauer-Gottwein, P.: Combining satellite radar altimetry, SAR surface soil moisture and GRACE total storage changes for hydrological model calibration in a large poorly gauged catchment, Hydrol. Earth Syst. Sci., 15, 1729 1743, doi:10.5194/hess-15-1729-2011, 2011.

Morris, C. S. and Gill, S. K.: Variation of Great-Lakes Water Levels Derived from Geosat Altimetry, Water Resour. Res., 30, 1009_ 1017, 1994.

Roux, E., da Silva, J. S., Getirana, A. C. V., Bonnet, M. P., Calmant, S., Martinez, J. M., and Seyler, F.: Producing time series of river water height by means of satellite radar altimetry-a comparative study, Hydrolog. Sci. J., 55, 104-120, 2010.

Schmugge, T. J., Kustas, W. P., Ritchie, J. C., Jackson, T. J., and Rango, A.: Remote sensing in hydrology, Adv. Water Resour., 25, 1367-1385, 2002.

Stisen, S. and Sandholt, I.: Evaluation of remote-sensing-based rainfall products through predictive capability in hydrological runoff modelling, Hydrol. Process., 24, 879-891, 2010.

Stisen, S., Sandholt, I., Norgaard, A., Fensholt, R., and Jensen, K. H.: Combining the triangle method with thermal inertia to estimate regional evapotranspiration - Applied to MSG-SEVIRI data in the Senegal River basin, Remote Sens. Environ., 112, 1242-1255, 2008.

Tang, Q. H., Gao, H. L., Lu, H., and Lettenmaier, D. P.: Remote sensing: hydrology, Prog. Phys. Geog., 33, 490-509, 2009.

Tapley, B. D., Bettadpur, S., Ries, J. C., Thompson, P. F., and Watkins, M. M.: GRACE measurements of mass variability in the Earth system, Science, 305, 503-505, 2004.

The World Bank: The Zambezi River Basin: A Multi-Sector Investment Opportunities Analysis, Vol. 3: State of the Basin, Washington DC, USA, 2010.

Wagner, W., Lemoine, G., and Rott, H.: A method for estimating soil moisture from ERS scatterometer and soil data, Remote Sens. Environ., 70, 191-207, 1999.

Zakharova, E. A., Kouraev, A. V., Cazenave, A., and Seyler, F.: Amazon River discharge estimated from TOPEX/Poseidon altimetry, C. R. Geosci., 338, 188-196, 2006. 